\title{
Lutando por novas narrativas em favelas e periferias: cidadanias complexas em meio a ativismos materiais e culturais
}

\author{
Struggling for new narratives in slums and peripheries: \\ complex citizenships amid material and cultural activisms
}

Thaisa Cristina Comelli [I]

\begin{abstract}
Resumo
0 presente artigo tem como objetivo debater e explorar os novos ativismos em favelas, cujo foco se posiciona na história, na cultura e na identidade desses territórios. Argumentamos aqui que, diferentemente do tradicional ativismo urbano comumente abordado na literatura (focado em demandas de natureza material), os novos ativismos buscam adicionar, a essas lutas, uma disputa pela narrativa sobre o território. Exploramos essas manifestações à luz de debates sobre a transição conceitual da cidadania e sobre identidades interseccionais. Especialmente, questionamos a existência de uma suposta identidade de favelado na qual os discursos e narrativas hegemônicas sobre a cidade, ora podem ser reproduzidos, ora podem ser subvertidos e utilizados na construção de lutas e ativismos urbanos insurgentes.
\end{abstract}

Palavras-chave: favela; ativismo urbano; cidadania insurgente; identidades urbanas.

\begin{abstract}
This article aims to discuss and explore new activisms in slums, focusing on the history, culture, and identity of such territories. We argue that, unlike the traditional urban activism commonly addressed in the literature (which focuses on demands of a material nature), the new activisms seek to add to such struggles a dispute over the narrative about the territory. We explore these manifestations in the light of debates about the conceptual transition of citizenship and intersectional identities. More specifically, we question the existence of a supposed slum-dweller identity in which hegemonic discourses and narratives about the city can be reproduced or subverted and used in the construction of insurgent urban struggles and activisms.
\end{abstract}

Keywords: slum; urban activism; insurgent citizenship; urban identities. 


\section{Introdução}

A construção epistemológica de temas relacionados às favelas é um caminho repleto de armadilhas. Por um lado, ainda é possível observar na literatura uma série de descrições e análises focadas na carência e na ausência; afinal, as favelas seguem sendo o lócus da pobreza urbana, da vulnerabilidade social e da segregação espacial nas grandes cidades brasileiras e do sul global. Por outro lado, há também na literatura estudos que buscam focar nos aspectos construtivos presentes em tais assentamentos; a cultura vibrante, o empreendedorismo criativo, a resiliência inabalável da favela e seus moradores. Assim, em geral, as narrativas hegemônicas sobre a favela seguem navegando como um pêndulo que flutua sobre dois opostos: o da romantização da pobreza urbana e o do reforço dos estereótipos negativos a ela atrelados.

Falar sobre "a favela" ou sobre "o morador de favela" no singular tampouco parece útil epistemologicamente. Afinal, são incontáveis as favelas, assim como diversas as histórias e peculiaridades que nelas habitam. Se considerarmos a variedade de formatos, status de formalidade, condicionantes ambientais, espectros demográficos, entre outros fatores, o termo favela parece demasiadamente genérico e descontextualizado; é uma espécie de categoria urbana inventada (Valladares, 2016).

Entretanto, o termo carrega consigo certa potência de atuar como fio condutor para lutas interseccionais. Em meio a tantas generalizações e estereótipos, quais são as possíveis contranarrativas sobre as tão diferentes favelas? Qual é a relação dessas narrativas com a cidade e as identidades complexas que nela habitam? Se tratamos de narrativas não hegemônicas ou insurgentes, em que medida são capazes de produzir transformações nos territórios das cidades? Pode a produção de contranarrativas ser considerada em si um tipo de ativismo urbano?

0 presente artigo parte dessas inquietações, buscando construir uma reflexão crítica sobre os novos ativismos nas favelas e assentamentos periféricos do País. Mais especificamente, busca-se, por meio deste trabalho, explorar o que aqui denominamos ativismo material e ativismo cultural urbano, em que a categoria favela, seus estereótipos e narrativas são contestados a partir ativismos e espaços de planejamento insurgente.

0 artigo divide-se em duas etapas principais: uma que visa a discutir o tema da cidadania e a complexidade de identidades "faveladas" e "periféricas" na transição da modernidade para a pós-modernidade; e outra particularmente focada em explorar panoramicamente os ativismos urbanos a partir da experiência das favelas cariocas. Pretende-se, com este debate, expandir o campo de estudos sobre as insurgências e os ativismos em espaços de vulnerabilidade social, adicionando, ao repertório tradicional de terra, moradia e infraestrutura, novas e criativas contestações sobre o espaço urbano baseadas em educação, cultura e história. 


\section{Cidadanias e identidades complexas}

\section{De universal a insurgente}

O sociólogo britânico Thomas Marshall (1967), ao analisar a evolução do conceito de cidadania ao longo dos séculos XIX e XX, sugere que há três elementos que nos permitem compreender sua trajetória nas sociedades ocidentais: o civil, o político e o social. No âmbito civil, desde o século XIX, a cidadania esteve intrinsecamente associada à liberdade individual e em consonância com os ideais modernos de Democracia Liberal. Já, no século XX - quando se vê como marco a garantia do sufrágio universal em vários países -, a cidadania passa a estar associada também aos direitos políticos de participar. Também é no século XX que a cidadania adquire nuanças sociais, quando aos direitos universais se passam a agregar ideias em torno de dignidade, bem-estar e desenvolvimento; é o caso de direitos como a educação básica de qualidade e o acesso à saúde.

A tese principal de Marshall é de que a cidadania é um status do qual gozam os indivíduos. Está associada a direitos e liberdades que são individuais e universais, o que contrasta com a construção histórica de classes sociais. Em outras palavras, "cidadania" e "classe social" são ideias incompatíveis, pois, enquanto a cidadania moderna é estabelecida nas bases da igualdade, a classe social é, em sua essência, um sistema de desigualdade (ibid.). É essa limitação intrínseca da cidadania nas sociedades capitalistas contemporâneas que termina por conferir, a determinados indivíduos ou grupos, o status de "cidadão de segunda classe" ou "subcidadão" (Kowarick, 1991).
Com o advento do fenômeno urbano, as limitações da cidadania universal passam a materializar-se também nos espaços das grandes cidades. Nesse contexto, o status de informalidade e subalternidade de muitos assentamentos é automaticamente transferido para seus moradores (Roy, 2011), criando uma espécie de divisão urbana de classes. Em países como o Brasil, os termos "suburbano", "periférico" ou "favelado" são mais do que relações geográficas dos indivíduos com a cidade; possuem uma carga simbólica de marginalidade diretamente ligada à posição social à qual certos indivíduos e grupos pertencem (Perlman, 1977).

Nesse contexto de desigualdades profundas, ao longo do século XX, o termo "Direito à Cidade" passou ser um instrumento de luta cidadã e denúncia de injustiças produzidas nos espaços urbanos. Afinal, se a cidade é produzida a várias mãos, o uso e o acesso a ela devem ser direito coletivo, em oposição a um privilégio individual (Lefebvre, 2001). Mais recentemente, esses debates passaram a adquirir novas nuanças, operando como bandeiras para uma participação efetiva na política urbana. Nessas interpretações, o Direito à Cidade não pode mais ser visto somente como um direito de acesso a bens e serviços, mas sim um direito de decidir sobre o rumo das cidades, de participar na produção e uso do espaço; de fazer escolhas, de deliberar, contestar e transformar desigualdades e injustiças (Harvey, 2014).

No Brasil, debates que relacionam cidadania e fenômeno urbano não são recentes. Na década de 1970, por exemplo, nomes como James Holston e Janice Perlman dedicaram-se a investigar os assentamentos autoconstruídos de cidades como Rio de Janeiro e São Paulo, na busca por compreender os estigmas, mitos 
e mecanismos de contestação cidadã atrelados aos territórios marginalizados e seus produtores (Perlman, 1977; Holston, 2013). No clássico Cidadania insurgente, Holston explora as cidadanias diferenciadas presentes no País, analisando, não só como o Estado legaliza e legitima as diferenças sociais, mas também como os próprios moradores periféricos e favelados passam a reconhecer-se como produtores e consumidores da vida urbana. Os cidadãos e cidadãs insurgentes passam, então, a demandar o reconhecimento estatal dos mesmos direitos que os cidadãos entrincheirados, privilegiados historicamente pelo aparato jurídico-normativo brasileiro (Holston, 2013, p. 22).

Há outras particularidades nos estudos de Holston relevantes para o contexto da presente análise. A primeira delas é o entendimento do urbano não só como pano de fundo das lutas cidadãs, mas como protagonista desses processos. Ou seja, luta-se pelo urbano e não somente no urbano. Além disso, o autor constata que, embora insurgentes e corrosivas, as lutas por cidadania dos moradores de periferias e favelas não constituem em si uma tentativa de revolucionar o sistema de produção de desigualdades socioespaciais; não são - ou pelo menos não eram - lutas anticapitalistas em suas essências. Os cidadãos e cidadãs insurgentes operam sob os mesmos paradigmas dos cidadãos entrincheirados, reivindicando direitos, como propriedade privada, direitos fundiários, legalização de assentamentos, entre outros. Apesar disso, o autor pondera que tais atos de reivindicação ainda podem ser considerados insurgentes, pois,

ao invés de meramente alimentar novas versões do hegemônico, o insurgente representa uma ruptura: permanece associado ao entrincheirado, mas num emaranhado corrosivo e desequilibrado que abala tanto o Estado como a sociedade. (Ibid., p. 35)

Posteriormente, o conceito de insurgência também foi trabalhado diretamente no campo das teorias de planejamento urbano, no qual se buscou abordar o papel da sociedade civil do sul global e seus urbanistas periféricos em meio à produção e contestação do território urbano. Debates de natureza crítica, baseados em teorias de democracia radical e teoria pós-colonial (entre outras linhas pós-modernas e pós-positivistas), focaram em explorar formas de planejamento baseadas no conflito, no dissenso e no fortalecimento dos saberes locais do "sul urbano" (Miraftab, 2004; Watson, 2013; Caldeira, 2017).

A partir dessa perspectiva insurgente do Sul, Miraftab explora, em diversos trabalhos, manifestações de ativismo nas quais cidadãos e cidadãs tomam as cidades em suas próprias mãos (Miraftab, 2004, 2009, 2020). A autora trabalha com os conceitos de espaços "convidados" e "inventados" para diferenciar as arenas de ativismo urbano e participação cidadã com maior ou menor grau de legitimidade perante o status quo. Miraftab reforça que ambos os espaços são democráticos, coproduzidos e frequentemente ocupados por ativistas insurgentes. Entretanto, ela nota a insuficiência dos espaços convidados em contraste com o caráter transformador dos espaços inventados de ativismo. Retomando escritos de Svirsky (2010), a autora argumenta que "o ativismo que busca apenas garantir os mecanismos da democracia representativa [é um] 'ativismo escravo'" (Svirsky, 2010, apud Miraftab, 2016). O planejamento urbano insurgente, 
defende Miraftab, deve ser capaz de corroer os próprios pilares no qual se sustenta o campo para construir um urbanismo mais humano (Miraftab, 2016).

Há de se destacar, entretanto, que os debates sobre cidadania urbana possuem dimensões e escalas territoriais cada vez mais complexas. Nesse sentido, debates sobre o comum político, sobre os comuns urbanos ou sobre as epistemologias do Sul estão dentre os que buscam superar as fronteiras tradicionais da modernidade - limitadas aos Estados-Nação - e reconstruir temas relacionados aos direitos e à cidadania com base em uma coletividade global (Dardot e Laval, 2017; Harvey, 2014; Sousa Santos, 2019). Em outras palavras, advoga-se, nessas linhas teóricas, que problemas socioespaciais produzidos em escala global devem ser debatidos e superados de maneira interescalar, democrática e igualmente global. Tal lógica se aplica também ao emblema do Direito à Cidade e às múltiplas lutas urbanas antidominação que se sobrepõem e dialogam na busca por tal direito (Harvey, 2014).

No caso de periferias, favelas e outros territórios do Sul marcados por autoconstrução, marginalização e cidadanias insurgentes (Caldeira, 2017), nota-se que há diversos desafios comuns e de caráter simultaneamente local e global a serem enfrentados coletivamente: são assentamentos que abrigam boa parte da população do mundo, ainda crescem em ritmo acelerado, frequentemente ocupando mais terra do que crescem em população e se verticalizam de forma densa e insalubre (ONU-Habitat, 2020).

Mas, para além de questões materiais e morfológicas, ou das tradicionais narrativas urbanas baseadas na carência e na ausência, há outras questões identitárias e de natureza simbólica que também conectam indivíduos e coletividades urbanas em torno de projetos comuns para as favelas e periferias do Sul. Aqui, argumenta-se que, ao reproduzir, misturar elementos, ressignificar e subverter estigmas e estereótipos, os "novos" cidadãos e cidadãs insurgentes das favelas e periferias engajam-se com o hegemônico em uma luta urbana com forte caráter cultural, educativo e identitário; uma luta por novas narrativas. A seguir, explorar-se-á, de forma breve, o caráter complexo e interseccional da identidade favelada e suas narrativas.

\section{Favela como identidade urbana complexa}

Não existimos isoladamente. Nosso senso de identidade está profundamente relacionado ao mundo, ao meio ambiente, à sociedade e aos demais seres que nos rodeiam (Mead, 1934). Assim como a transição da modernidade para a pós-modernidade trouxe a fragmentação do discurso único e das visões de mundo hegemônicas (Sousa Santos, 2002), também pôde-se observar uma fragmentação das "paisagens culturais" de classe, gênero, sexualidade, etnicidade e nacionalidade antes asseguradas pelo discurso moderno (Hall e Du Gay, 1996, p. 275). A noção do "eu" e sua relação com o tempo e com o espaço passam a ser mais fluidas e voláteis, dificultando nossa localização como indivíduos sociais e cidadãos.

A crise identitária da modernidade, no entanto, não passa de uma miragem. Uma identidade individual ou coletiva estática, coesa e completa jamais existiu (ibid.), principalmente se analisamos essa identidade de maneira longitudinal. Assim como o conceito de 
cidadania um dia esteve intrinsecamente relacionado à noção de Estado-nação e agora se expande para uma pluralidade de setores sociais e escalas territoriais, as identidades culturais também se encontram em um momento de expansão e ressignificação coletiva.

Nesse sentido, análises que relacionam cidade e identidade também devem ser capazes de operar com fluidez, já que, na prática, os corpos e as causas movem-se livremente pelo espaço urbano. Não faz sentido descrever e analisar moradores de cidades meramente com base no local onde nasceram ou onde moram; estamos todos continuamente construindo vínculos e relações identitárias com diferentes espaços da cidade e, em um mundo globalizado, também com diversas cidades e territórios simultaneamente. Além disso, construímos relações identitárias que independem dos espaços físicos das cidades; vínculos que se criam por meio de causas e interesses.

A partir dessa lógica, nota-se a dificuldade de tratar da suposta identidade do morador de favela, do subúrbio ou da periferia para a construção de lutas urbanas de caráter insurgente. Em alguns casos, tal categoria pode funcionar como um mero reforço de estereótipos gerados a partir de visões de mundo hegemônicas sobre a cidade. Em outros, essa identidade pode ser capaz de traduzir e conectar as pluralidades de corpos e de demandas urbanas; pode servir como um fio condutor para narrativas cidadãs contra-hegemônicas. De certa forma, a identidade periférica/favelada é uma espécie de tensão que simultaneamente reduz e conecta: conecta as identidades complexas que lutam pelo Direito à Cidade, enquanto as compacta e as reduz a um determinado tipo de território.
Em meio a tal "complexidade identitária", há certos aspectos e demandas que tendem a ganhar centralidade nos debates político-urbanos contemporâneos. Nos movimentos estudados em Cidadania insurgente (Holston, 2013), é o conflito entre classes sociais que ganha destaque e se mostra como fio condutor de lutas periféricas que usam a linguagem da cidadania. Há também, em outros movimentos e ativismos periféricos e favelados do Sul, uma crescente ênfase em questões de gênero, raça, religião ou etnia (Doshi, 2012). Questões raciais, em particular, possuem forte conexão com a história de urbanização do Brasil. No país, mais de $70 \%$ dos mais pobres são negros; e, segundo mapas raciais, ${ }^{1}$ pretos, negros e pardos são a maioria em periferias e favelas, enquanto aos brancos ficam reservados os bairros centrais, seguros, arejados e com os melhores serviços das grandes cidades.

Há também elementos de natureza mais simbólica e afetiva que conectam moradores de favela para além de classe, raça ou gênero. Segundo Jovchelovitch e Priego-Hernandez (2013), embora a identidade do morador de favela esteja fortemente associada à sua posição social, há três discursos/ narrativas identitárias que prevalecem no momento de relacionarem a si mesmos com seus locais de moradia: o sentimento de pertença (apego afetivo ao espaço físico, ao lugar), a tentativa de rejeitar os medos atrelados ao lugar e a percepção de coesão social (ligada a solidariedade e ao capital social na comunidade). Em outras palavras, a relação identitária do favelado com seu local de moradia frequentemente extravasa questões de natureza corpórea e material, adquirindo nuanças 
afetivas e simbólicas. Enfim, trata-se de uma noção fluida e relacional, com conexões que se formam em diferentes tempos e escalas.

Já Guareschi et al. (2002) observam como o discurso dos moradores de favela, especialmente os jovens, mescla de maneira quase indissociável ideias sobre raça e classe, prevalecendo a última como explicação predominante para sua atual realidade. As experiências sobre discriminação vêm constantemente assimiladas a noções difusas sobre cidadania em que, para muitos, sair do espaço físico da favela é o único modo de adquirir direitos e "ser alguém". Para alguns entrevistados, é o próprio território da favela, somado aos condicionantes de classe e raça, que impossibilita a conquista do status de cidadania plena (ibid.).

Também, nas diversas experiências de resistências antirremoção e movimentos pelo direito à terra e à moradia em favelas, é possível observar como raça, gênero e cultura operam como fatores difusos, mas determinantes para a criação de identidades políticas interseccionais e complexas. Tais identidades se rearticulam no tempo e no espaço em função de seus membros, líderes e demandas, produzindo uma pluralidade de "paisagens culturais" urbanas (Keisha-Khan, 2004; Alves, 2012).

Finalmente, destaca-se o papel de manifestações culturais diversas que, por associadas ou produzidas pelas favelas, periferias e seus moradores, podem operar como instrumentos ou catalisadores de identidades interseccionais e lutas urbanas (Guasco, 2001; Patrocínio, 2013). Apesar de não necessariamente conectadas a movimentos sociais e ativismos urbanos, contribuem para a construção de identidades subalternas/periféricas que, ora reivindicam igualdade de direitos, ora apropriam-se de seus estereótipos para construir críticas baseadas na diferença e na diversidade.

$$
\begin{array}{r}
\text { "E se não resistir e desocupar? } \\
\text { Entregar tudo pra ele então, o que será? [...] } \\
\text { A beleza de um povo } \\
\text { A favela não sucumbe } \\
\text { Meu lado África aflora, me redime } \\
\text { O anjo do mal alicia o menininho } \\
\text { Toda noite alguém morre } \\
\text { Preto ou pobre por aqui". } \\
\text { (Criolo, 2014) }
\end{array}
$$

\section{"Sou mulher, sou negra, meu cabelo é duro Forte, autoritária e às vezes frágil, eu assumo Minha fragilidade não diminui minha força [...] Sou mulher destemida, minha marra vem do gueto".} (MC Carol, 2016)

Nos dois trechos acima, ao mesmo tempo que se crítica a opressão do favelado ou favelada a partir de diferentes sistemas, tal opressão é justaposta à forca, à vitalidade e à beleza dessas identidades complexas e seus territórios de origem. Ambas as canções são narrativas periféricas/faveladas com forte conteúdo político e cultural; evidenciam a complexidade identitária das favelas, mas também evidenciam certos fios condutores formados por geografias globais e territórios urbanos marginalizados: África, favela, gueto.

Enfim, o panorama traçado nesta seção busca evidenciar diferentes matizes de discurso que moldam identidades contemporâneas a partir da imagem da favela e da periferia. A ideia de "favela como identidade complexa" significa, então, que há diferentes ênfases e nuanças (de classe, raça, gênero, espaço) que podem aflorar nas manifestações culturais e políticas e no discurso dos favelados e faveladas em função do contexto em questão.

Com frequência, e principalmente no caso de ativismos urbanos contemporâneos, a identidade de favelado ou favelada vem sendo utilizada como produto e produtora 
cultural e política. Ou seja, é uma identidade complexa que opera a partir da subversão de estereótipos e como bandeira de lutas urbanas insurgentes. Assim, ao invés de reduzir o favelado à favela, o ativismo urbano contemporâneo utiliza o emblema da categoria favela como ponto de partida e fio condutor para construir demandas e narrativas.

\section{Ativismo favelado e periférico}

O termo "ativismo" no contexto deste trabalho se refere a arenas participativas ou ações contenciosas com caráter contra-hegemônico que desejam contestar ou reivindicar algo em nome de uma coletividade maior. A seguir, trataremos de formatos de ativismo que dialogam com o tema da cidadania insurgente e com os assentamentos autoconstruídos do sul global, particularmente periferias e favelas. As reflexões têm como base um trabalho contínuo de observação participante e colaboração com coletivos urbanos e projetos sociais em favelas da Zona Sul, Zona Norte e Zona Oeste do Rio de Janeiro.

Quanto à estrutura analítica do texto, os debates dividem-se em duas linhas gerais, que aqui são compreendidas como dois fios condutores que conectam as complexas identidades e lutas nas favelas do sul global. 0 primeiro fio condutor é o material, que corresponde às lutas por terra e moradia. São os ativismos "tradicionais" que surgiram em torno de diferentes assentamentos autoconstruídos ao longo do século $X X$, em muitos casos a partir de ameaças de remoção. Somado a esse importante elo material, argumenta-se, aqui, haver também um elo imaterial que começa a surgir nas décadas mais recentes. Esse segundo fio condutor é caracterizado por uma ênfase em aspectos identitários, na trajetória história particular de cada assentamento autoconstruído e em manifestações artísticas, educativas e culturais. Argumentamos que esse tipo de "ativismo cultural urbano" representa uma série de lutas por novas narrativas sobre as favelas. Embora seja possível sugerir que as lutas materiais sejam mais antigas e as imateriais mais recentes, destaca-se que ambas se encontram justapostas e intrinsecamente conectadas nos territórios de favelas e periferias. Ou seja, mesmo estando aqui divididas, na prática são de difícil dissociação.

\section{Lutando por terra, moradia e infraestrutura: ativismo material}

A gênese do ativismo em favelas não é datada com precisão, provavelmente porque se confunde com a natureza e o surgimento das favelas. Desde que a favela foi identificada como um fenômeno urbano de peso, políticas públicas flutuaram entre iniciativas de remoção, cooptação, assistencialismo e, como hoje se observa mais comumente, projetos de urbanização com enfoques em habitação, infraestrutura e qualificação ou criação de espaços públicos. Assim, tanto em oposição a ações higienistas do Estado quanto com o objetivo de promover melhores condições de vida para moradores, o ativismo na forma de ações coletivas antirremoção ou mutirões comunitários para a construção de infraestrutura e espaços públicos fizeram parte da história de inúmeras favelas do País, fortalecendo a imagem de coesão atribuída a esses espaços e seus moradores (Gonçalves, 2013). 
Durante a primeira metade do século XX, as remoções prevaleceram como paradigma de ação do poder público, legitimadas pelas narrativas da "favela como problema" (Burgos, 1998, p. 34) e pela construção da identidade do favelado como vagabundo, criminoso ou incapaz. Quanto ao status de cidadania, Santos (1979) recorda que, por volta da década de 1930, o Brasil vivia uma situação de "cidadania regulada", na qual aqueles que não possuíam ocupações (emprego, vínculo) identificadas por lei eram considerados pré-cidadãos. Além disso, no que tange à participação política, a constituição vigente da época restringia o voto aos analfabetos, o que em geral englobava boa parte dos moradores de favela (Burgos, 1998).

Nessa época, a cidadania e os direitos civis e políticos ainda não eram contestados em massa nas favelas. Tampouco a identidade do favelado era comumente utilizada como bandeira para reivindicações mais amplas. Entretanto, a busca por melhores condições de vida nesses assentamentos e a própria condição de vulnerabilidade socioespacial foram, pouco a pouco, sendo cristalizadas na forma de associações de moradores, nas quais as "lideranças políticas", escolhidas democraticamente ou não, advogavam pelos interesses dos demais habitantes. No Rio de Janeiro, a atuação do Serviço Especial de Recuperação de Favelas e Habitações Anti-Higiênicas (Serfha), no início dos anos 1960, estimulou a criação de diversas associações de moradores nas favelas em que ainda não existiam, de forma a facilitar o diálogo da população com o poder público. A comunicação entre líderes e ativistas de diferentes favelas culminou na criação, em 1963, da Federação das Associações de Favelas do Estado da Guanabara (Fafeg/ Faferj), uma das grandes representações de favelas até os dias atuais (Gonçalves, 2013).
Também nessa época, profissionais como Carlos Nelson F. dos Santos despontaram como pioneiros de processos participativos em favelas, em que a figura do técnico perdia centralidade para adquirir um caráter de facilitador de interesses locais. A partir de experiências emblemáticas, como a da favela Brás de Pina nos anos 1960 (Santos, 1981), a pedagogia civilizatória do modernismo brasileiro foi, pouco a pouco, sendo contestada e substituída por um estímulo dos saberes e capacidades locais. Nesse modelo, eram os próprios moradores e ativistas locais os protagonistas, não os arquitetos e urbanistas. Mesmo assim, cabe destacar que os padrões de assistencialismo e as trocas de favores urbanos nunca desapareceram por completo (Gonçalves, 2013).

$\mathrm{Na}$ segunda metade dos anos 1960 e a partir dos anos 1970, a ditadura militar contribuiu para um enfraquecimento do ativismo em favelas e para a cooptação de algumas de suas lideranças (Valladares, 2000). Algumas associações sobreviveram, alegando serem apolíticas e de caráter exclusivamente técnico. Em alguns casos, notou-se que a própria associação de moradores atuou em aliança com o poder público para a remoção massiva e/ou realocação de assentamentos. Perlman (1977) descreve esse processo de aliança do ativismo local com os poderes hegemônicos da cidade a partir de seu trabalho etnográfico no Morro da Catacumba.

Já nos anos 1980, com a reabertura parcial do regime militar, o ativismo mais combativo e contra-hegemônico nas favelas se reorganiza novamente. Em um contexto nacional de redemocratização, nota-se, também, a participação ativa de movimentos e associações de favelados em arenas como o Movimento Nacional pela Reforma Urbana (MNRU). 
Nesse sentido, cabe destacar que o MNRU foi uma das pedras fundamentais para a construção de instrumentos normativos urbanos até hoje vigentes, como é o caso do Estatuto da Cidade, promulgado em 2001 (Maricato, 2017).

Apesar da importância das associações de moradores para o ativismo urbano em favelas, é importante destacar que o papel dessas organizações se transforma e se complexifica com o tempo. No caso do Rio de janeiro, particularmente, as associações possuem um papel ambivalente no que tange às estruturas de poder da cidade; ora atuam de forma insurgente e contra-hegemônica (na forma de movimentos antirremoção ou em prol de direitos), ora atuam em alianças pouco transparentes com o poder público e com poderes paralelos (facções do tráfico e milícias). Para além das associações "oficiais" de moradores, há ainda uma constelação de grupos políticos com diferenças e dissidências internas de cunho ideológico e identitário, o que contribui por moldar o perfil político das diferentes favelas da cidade. Em suma: embora o fio condutor da terra, da moradia e da infraestrutura urbana tenha contribuído para a formação de diversas associações de favelados no século XX, nem toda associação ou coletividade favelada é necessariamente parte de um ativismo insurgente (Burgos, 1998).

Em meio a essa complexidade de alianças políticas e visões de mundo, fato é que uma sequência de lutas históricas de natureza material contribuiu para a mudança de paradigma no que tange à atuação do poder público em assentamentos autoconstruídos (Conde, 2004). O processo de redemocratização alavancou esse processo, embora o paradigma de remoção nunca tenha desaparecido por completo. Há, ainda hoje, casos emblemáticos como o da vila Autódromo, que suscitou experiências de planejamento conflitivo em meio às disputas urbanas relacionadas aos megaeventos (Vainer et al., 2013).

Casos de remoção forçada e em massa, entretanto, deixaram de ser tão dominantes no Brasil. A partir dos anos 1990, principalmente após o Favela Bairro, a ideia de integrar a favela na cidade - com um discurso focado na cidadania e nos direitos - passa a ser o paradigma dominante de ação do Estado. Nota-se, hoje, que a tônica da maior parte dos programas de urbanização de favela contemporâneos é de integração espacial e participação cidadã. Ademais, o que antes eram experiências locais de urbanização de favelas passou a adquirir importância e escala nacional. No Brasil, há o paradigmático caso do Programa de Aceleração do Crescimento (PAC), que, além de injetar bilhões na urbanização de favelas, institucionalizou espaços convidados de participação a partir da obrigatoriedade do "trabalho social" (Cardoso e Denaldi, 2018). No caso do Rio de Janeiro, o trabalho social transformou-se em um "canteiro social", espaço físico de diálogo, orientação e negociação em torno de questões de infraestrutura, moradia, mobilidade, entre outros temas (Comelli e Silva, 2018).

Iniciativas como o Canteiro Social do PAC no Rio de Janeiro ilustram o conceito de "espaços convidados" de planejamento (Miraftab, 2004), nos quais a participação cidadã é legitimada pelo Estado e pelos status quo. Apesar de relevantes do ponto de vista da democratização da produção do espaço urbano, os espaços convidados nesses territórios se mostraram ainda insuficientes para a incorporação efetiva das demandas de moradores nos projetos urbanos. Mesmo assim, a existência de projetos urbanos de grande porte com arenas 
"convidadas" de participação também contribuiu para catalisar movimentos e ativismos insurgentes preexistentes, os quais se articulam em torno de tais projetos para produzir "espaços inventados" de ativismo e demandas materiais concretas (Miraftab, 2020).

Um exemplo dessa dinâmica co-constituição dos espaços convidados e inventados de ativismo em favelas é o caso do teleférico como parte do PAC 2 na Rocinha. Enquanto nos espaços convidados do Canteiro Social se buscava referendar a instalação de um teleférico na favela com base em um discurso de mobilidade; nos espaços inventados insurgentes, favelados e seus grupos de apoio encontraram, na luta por saneamento básico, um fio condutor para a construção de um discurso contra-hegemônico. A campanha do "telefante" dizia: "saneamento básico sim, elefante branco não". No caso da Rocinha, o saneamento foi o fio condutor material dos ativismos urbanos no contexto do PAC.

Embora os ativismos de natureza material sigam relevantes como fio condutor de lutas urbanas, cabe destacar novos fenômenos que começam a afetar favelas e periferias e desencadear outros tipos de ativismo. Nas favelas da Zona Sul do Rio de Janeiro, por exemplo, há uma conjuntura de fatores e políticas que terminaram contribuindo, por volta dos anos 2000, para um crescimento do turismo em favelas, além do aumento do valor dos imóveis para venda e aluguel nesses territórios (Comelli, Anguelovski e Chu, 2018). O turismo de favelas, particularmente, não é um fenômeno tão recente (Frenzel, Koens e Steinbrink, 2012), mas, com as políticas de urbanização, legalização fundiária e pacificação, contribui

Figura 1 - Ilustração criada para a campanha do "telefante"

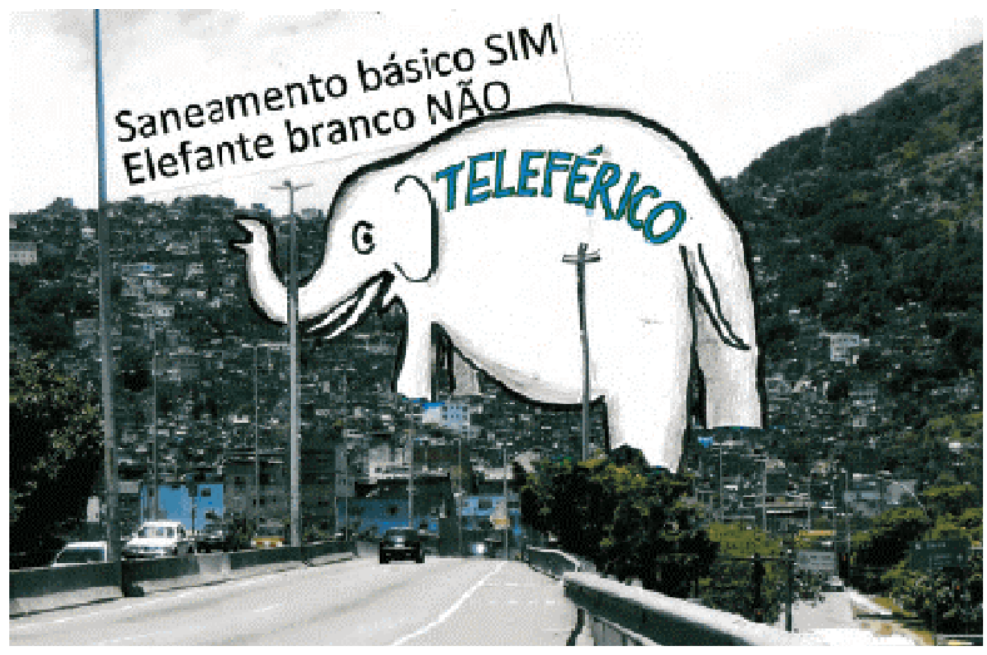

Fonte: coletivo Rocinha sem Fronteiras. 
para a entrada de empreendedores e moradores estrangeiros e de classe média/alta nesses espaços (Comelli, Anguelovski e Chu, 2018).

Em meio a percepções ambivalentes e conflituosas sobre esses novos atores e dinâmicas urbanas em jogo (ibid.), os moradores das favelas e ativistas urbanos naturalmente passaram a reagir a essa nova realidade. Em oposição a modelos de turismo mais invasivos, como o "turismo de safari", ativistas e moradores locais de diversas favelas e periferias passam a organizar-se para promover um "turismo de base comunitária" (Fagerlande, 2018), focado na produção de uma narrativa local com forte teor político.

O caso do turismo de base comunitária contribui para exemplificar como os fenômenos contemporâneos da cidade catalisam outros tipos de ativismo periférico de natureza imaterial, ou seja, focados no saber, na história e em outras narrativas sobre os territórios marginalizados. Argumenta-se, neste artigo, que, embora não tradicionalmente classificadas como movimentos sociais ou lutas urbanas, essas iniciativas produzem um ativismo com potencial transformador, pois objetivam mostrar a potência da favela e a complexidade histórica e identitária de seus moradores.

\section{Lutando por novas narrativas: ativismo cultural urbano}

Nas décadas recentes, uma somatória de investimentos e políticas urbanas, econômicas e de segurança estimulou uma suposta "abertura" das favelas para o mundo (e para o capital global). 0 ápice desse processo, ao menos no Rio de Janeiro, foi o período imediatamente anterior aos megaeventos (Comelli,
Anguelovski e Chu, 2018). A guinada definitiva das cidades brasileiras rumo a padrões de governança neoliberais afetou também muitas favelas. Aos poucos, em favelas pacificadas e próximas a outras atrações turísticas, novos albergues, hotéis, galerias de arte e restaurantes voltados para o consumo do público de classe média, alta e estrangeiro passaram a ser comuns na paisagem urbana (Fagerlande, 2018). Isso resultou no aumento de preços e em mudanças nas dinâmicas culturais e sociais dos moradores mais antigos.

Entretanto, o acesso a novas oportunidades políticas e econômicas também abriu portas para ações insurgentes com enfoque no espaço urbano, como é o caso dos ativismos aqui abordados. Em pesquisa ainda em curso, desde o ano da copa do mundo (2014), começou-se a investigar movimentos, empresas, coletivos e associações focados em promover novas narrativas sobre as favelas. A observação participante em museus de favela, grupos de turismo de base comunitária, associações com enfoque ambiental e veículos de mídia independente incluiu tanto visitas presenciais em eventos, palestras e rodas de conversa, quanto o acompanhamento desses grupos nas redes sociais.

O Quadro 1 ilustra algumas das principais iniciativas acompanhadas ao longo dos últimos sete anos. Aqui, consideramos essas iniciativas espaços inventados de ativismo cultural urbano. Algumas delas não são necessariamente novas. Há, por exemplo, o caso da rádio comunitária das favelas do Cantagalo/Pavão-Pavãozinho que, segundo ativistas locais, é a primeira rádio comunitária em uma favela da cidade, fundada ainda nos anos 1990. Entretanto, as instalações do local estiveram sucateadas por muitos anos e, somente por meio 
Quadro 1 - Alguns espaços e grupos de ativismos monitorados para a análise deste artigo

\begin{tabular}{|c|c|c|c|}
\hline Sede & Grupo & $\begin{array}{l}\text { Ano de fundação/ } \\
\text { inauguração }\end{array}$ & $\begin{array}{c}\text { Área de atuação } \\
\text { principal }\end{array}$ \\
\hline Favela do Horto & Museu Horto Florestal & Não disponível & $\begin{array}{c}\text { História / } \\
\text { Preservação ambiental }\end{array}$ \\
\hline Complexo da Maré & Museu da Maré & 2006 & História \\
\hline Vila Autódromo & Museu das Remoções & 2016 & História \\
\hline $\begin{array}{l}\text { Favelas Cantagalo / } \\
\text { Pavão-pavãozinho }\end{array}$ & $\begin{array}{l}\text { Museu de Favela } \\
\text { (MUF) }\end{array}$ & 2008 & História \\
\hline $\begin{array}{l}\text { Favelas Babilônia / Chapéu } \\
\text { mangueira }\end{array}$ & CoopBabilônia & 1997 / 2006 & Preservação ambiental \\
\hline $\mathrm{N} / \mathrm{a}$ & $\begin{array}{l}\text { Agência de Notícias } \\
\text { das Favelas }\end{array}$ & $2001 / 2005$ & Comunicação \\
\hline Favela da Rocinha & Jornal Fala Roça & 2012 & Comunicação \\
\hline Favela da Rocinha & Museu Sankofa & 2008 & História \\
\hline Complexo do Alemão & $\begin{array}{l}\text { Jornal Voz das } \\
\text { Comunidades }\end{array}$ & 2005 & Comunicação \\
\hline Cantagalo /Pavão-pavãozinho & $\begin{array}{l}\text { Rádio Comunitária } \\
\text { Cantagalo }\end{array}$ & 2018 & Comunicação \\
\hline
\end{tabular}

Obs: as datas de fundação não são precisas e podem variar, já que muitos desses espaços se consolidaram de forma gradual ou, em alguns casos, tiveram períodos de pouca atividade.

de doações privadas e eventos beneficentes, foi possível uma reativação do local no ano de 2018. Outras iniciativas, como é o caso da Agência de Notícias das Favelas (ANF), começaram como pequenos veículos independentes (2001), adquirindo o status de ONG posteriormente, em 2005. Em suma, o ponto é que o acúmulo dessas iniciativas culturais é relativamente recente.

Cada organização possui uma história à parte, surgindo a partir de uma conjuntura de mobilizações comunitárias e parcerias com setores da sociedade civil e instituições, como universidades e outros grupos de ativismo da cidade. Há, por exemplo, o caso do Museu Sankofa na Rocinha, que surge a partir de diferentes eventos e fóruns culturais na favela; ou o caso do Museu das Remoções na Vila Autódromo, que surge a partir da experiência de planejamento conflitivo antirremoção (Vainer et al., 2013). Em ambos os casos, há em comum a intenção de preservar a memória e a história da favela. O fio condutor das lutas materiais ainda é parte central desses ativismos culturais e educativos, mas o repertório dos espaços insurgentes é outro: consiste em produzir novas narrativas sobre o território das favelas e periferias. 
O conteúdo de cada repertório de ação e narrativa varia também em função do contexto particular desses espaços de ativismo cultural, de seus enfoques temáticos e objetivos coletivos. No caso do Museu do Horto, por exemplo, há uma tônica ambiental e de sustentabilidade que se mistura com a luta antirremoção. No caso do Museu Sankofa, a história da favela é contada a partir de um passeio no próprio espaço urbano, no qual é possível observar diferentes tipologias arquitetônicas, além de becos e vielas; ou seja, o museu é a céu aberto e a história é contada a partir de um trajeto cuidadosamente selecionado pelos ativistas, em que narrativas urbanas se misturam com narrativas políticas. No caso do Museu das Remoções, como diz o próprio nome, a tônica é a história das políticas remocionistas que marcaram a cidade e seus habitantes mais vulneráveis.

A temporalidade do surgimento dos museus chama a atenção; evidencia um fortalecimento do ativismo tradicional, somado a um aprendizado contínuo sobre o espaço urbano e sua história. Tal saber passa a ser transmitido para o resto da população a partir da brecha deixada por esse momento de abertura das favelas. Ademais, ressalta-se aqui o importante papel dos museus de favela para a construção de uma cidadania ativa e insurgente em escala local, nacional e global, em que o registro das lutas e da própria existência das favelas é um constante lembrete do Direito à Cidade.

A resistência foi superimportante para a gente ficar naquela comunidade. [...] A favela é nossa, é um direito nosso, porque ela faz parte da cidade, e isso não é novo. [...] O que nos sobra é um direito nosso permanecer lá. Então quando a gente fala em urbanizar a favela é dar direito à terra, sua história. Porque não é só sua casa, é a nossa história. Nós construímos nossas casas para morar, e não para ser movido. Nós não somos bichos para ser removidos. Nós temos que ter muito essa consciência, do direito ao território. (Líder da Vila Autódromo, em Palestra pública, 2018)

Nesse contexto, cabe lembrar também o importante papel dos museus de favela como ponte e conexão entre os diferentes habitantes da cidade. Atualmente, muitos dos museus e seus ativistas encontram-se engajados com o turismo de base comunitária, o que ajuda a abrir canais de comunicação com um setor da população não tão engajado politicamente. Há, nesse caso, o compromisso de sensibilizar aqueles alheios à realidade das favelas para essas contranarrativas.

Os turistas que vêm pra cá ficam impressionados com a organização que nós temos aqui. As favelas do Rio de Janeiro foram retratadas pela mídia por muito tempo como locais violentos. [...] A Babilônia não pode ser vista como um gueto, uma área dominada por uma ou outra facção. Ela tem que ser entendida como um espaço público em si mesma, onde as pessoas sobem e visitam, entendem sobre a vida diária das pessoas aqui, interagem [...]. (Morador da favela da Babilônia e membro da Cooperativa de reflorestamento em entrevista semiestruturada, 2015)

No que tange a questões identitárias, em muitos casos, os ativistas que trabalham com o turismo de base comunitária também enxergam a si mesmos como membros de 
uma resistência urbana, em oposição direta aos poderes oficiais e paralelos que operam nas favelas, ou seja, o Estado, facções do tráfico e milícias.

Aqui a gente habita a violência. [...] 0 fato da gente continuar trabalhando, em meio a isso tudo que está acontecendo [violência e intervenção militar], já é uma forma de resistência. (Morador e ativista do Museu Sankofa na Rocinha em roda de conversa, 2018)

Finalmente, destaca-se o papel dos veículos de comunicação independentes, por meio dos quais se noticia tanto o que ocorre dentro das próprias favelas ou em outras favelas, quanto o que ocorre no resto da cidade. Além das notícias que, de modo semelhante ao caso dos museus, são histórias contadas a partir da vivência e da experiência dos próprios moradores, os jornais e rádios comunitários frequentemente denunciam ações do poder público e abrem espaço para formatos de participação mais combativa e insurgente, ou seja, costumam apresentar um discurso menos cooptado pelas narrativas hegemônicas sobre a cidade. No trecho abaixo, por exemplo, um morador e colaborador da Agência de Notícias das Favelas reflete sobre a identidade e a condição de favelado como uma construção de autoestima e apego ao lugar de origem.

O nascimento de um favelado ocorre quando ele consegue projetar, para dentro e fora de si, um sentimento de pertencimento à sua comunidade. O favelado nasce quando consegue enxergar aquele pedaço de terra, excluído política e socialmente, como seu ponto de origem. $O$ favelado vem à vida quando a favela se torna seu ponto de partida para pensar e explorar o mundo tanto na esfera geográfica quanto em seu posicionamento e senso crítico junto à sociedade e suas mazelas. Acreditem: isto pode demorar a acontecer. (Morador do Jacarezinho e colaborador da ANF, 2017)

A fala deste ativista traduz o argumento deste trabalho de que a luta por novas narrativas é um fio condutor de ativismo urbano que conecta as identidades complexas dos moradores e moradoras de favela e contribui para a produção de espaços de planejamento insurgente. 0 fio condutor do ativismo material, somado a um sentimento de pertença e a construção de uma identidade matizada, contribui para a produção de contranarrativas e novas demandas cidadãs. Embora as lutas materiais sigam sendo importantes para os favelados, pois se referem a necessidades e direitos básicos, as lutas por narrativas mostram a capacidade desses cidadãos e cidadãs de subverter um estereótipo negativo e transformá-lo em uma bandeira de luta. A identidade complexa de favelado, quando politizada, pode ser um ponto de partida para uma visão crítica sobre a cidade. Nesse sentido, o ativismo cultural urbano possui potencial insurgente e transformador justamente por sua capacidade de corroer as fundações do estigma e da marginalidade.

\section{Reflexões finais}

Ao longo deste artigo, buscou-se conectar os temas da cidadania, da identidade cultural e dos ativismos urbanos no contexto de favelas e periferias. 0 objetivo principal foi explorar um repertório contínuo de ações e espaços insurgentes que passam a adquirir novas 
matizes com o tempo. 0 argumento principal é o de que, embora mais sutis, lentos e difusos, o trabalho dos ativismos ligados à história e à cultura das favelas possui um potencial transformador tão importante a longo prazo quando as lutas tradicionais por terra, habitação e infraestrutura.

Neste momento final, deseja-se também recordar e desenvolver alguns pontos importantes para os debates travados neste trabalho. 0 primeiro deles é a necessidade de compreender a cidadania insurgente para além do mero conflito de classes. 0 entendimento do favelado ou morador de periferia como oprimido urbano ou subalterno, embora fundamental para a compreensão da segregação e das dinâmicas socioespaciais, não é mais suficiente para uma leitura contemporânea dos novos ativismos. 0 conflito de classes ainda existe e a produção capitalista do espaço ainda afeta severamente as dinâmicas socioespaciais. Entretanto, à camada de classes, é fundamental que se adicionem outros matizes identitários, como as questões etárias, de gênero, sexualidade, raça, entre outros.
Uma identidade de favelado ou favelada não pode existir como categoria estática e perene. As identidades, tanto dos moradores de favela quanto de qualquer outro morador da cidade, são fluidas e migram entre causas e espaços ao longo do tempo. Essa compreensão e flexibilização da noção de identidade no tempo/espaço/causa (para além do indivíduo) é uma premissa básica para a construção da teoria urbana crítica sobre favelas rumo à pós-modernidade. 0 morador de favela é e não é favelado, simultaneamente. É cidadão universal na medida em que busca a equiparação de direitos e na medida em que se percebe merecedor de terra, moradia e infraestrutura por sua condição de produtor e consumidor do urbano. Mas é favelado também, na medida em percebe sua relação com o urbano como motivo de orgulho e de subversão de um discurso hegemônico. É favelado em seus próprios termos e, especialmente por isso, é capaz de produzir novas e legítimas narrativas sobre seu território de origem e moradia.

\section{[I] https://orcid.org/0000-0003-3173-2602}

Universidade Federal do Rio de Janeiro, Faculdade de Arquitetura e Urbanismo, Programa de Pós-Graduação em Urbanismo. Rio de Janeiro, RJ/Brasil.

thaisacomelli@ufrj.br

\section{Nota de agradecimento}

O presente trabalho foi realizado com apoio da Coordenação de Aperfeiçoamento de Pessoal de Nível Superior (Capes), Código de Financiamento 001. A pesquisa em curso conta também com o apoio do Conselho Nacional de Desenvolvimento Científico e Tecnológico (CNPq), processo $141281 / 2017-0$. 


\section{Notas}

(1) Disponível em: <https://www.cidadessustentaveis.org.br/arquivos/mapa_desigualdade_2018_ apresentacao.pdf>. Acesso em: 28 dez 2020.

(2) Trecho extraído de coluna da Agência de Notícias das Favelas. Disponível em: https://www.anf. org.br/quando-nasce-um-favelado/. Acesso em: 5 jan 2019.

\section{Referências}

ALVES, J. A. (2012). Dialectics of the African Diaspora: the glocality of race and resistance in the Brazilian economy of violence. Cultural Dynamics, v. 24, n. 1, pp. 31-57.

BURGOS, M. B. (1998). "Dos parques proletários ao Favela-Bairro: as políticas públicas nas favelas do Rio de Janeiro". In: ZALUAR, A; ALVITO, M (orgs.). Um século de favela. Rio de Janeiro, Ed. FGV.

CALDEIRA, T. (2017). Peripheral urbanization: Autoconstruction, transversal logics, and politics in cities of the global south. Environment and Planning D: Society and Space, v. 35, n. 1, pp. 3-20.

CARDOSO, A. L.; DENALDI, R. (2018). Urbanização de favelas no Brasil: um balanço preliminar do PAC. Rio de Janeiro, Letra Capital.

COMELLI, T; ANGUELOVSKI, I; CHU, E. (2018). Socio-spatial legibility, discipline, and gentrification through favela upgrading in Rio de Janeiro. City, v. 22, n. 5-6, pp. 1-24.

COMELLI, T; SILVA, R. (2018). Participação nas favelas cariocas contemporâneas: uma reflexão à luz dos conceitos de emancipação e deliberação. In: III SEMINÁRIO NACIONAL SOBRE URBANIZAÇÃO DE FAVELAS. Anais... Salvador, UCSAL.

CONDE, L. (2004). Favela-Bairro, uma outra história da cidade do Rio de Janeiro: 1993/2000 uma ação urbanizadora para o Rio de Janeiro. Rio de Janeiro, ViverCidades.

DARDOT, P; LAVAL, C. (2017). Comum: ensaio sobre a revolução no século XXI. São Paulo, Boitempo.

DOSHI, S. (2012). "The politics of persuasion: gendered slum citizenship in neoliberal Mumbai". In: DESAI, R.; SANYAL, R. (orgs.). Urbanizing citizenship: contested spaces in Indian cities. Nova Delhi, Sage.

FAGERLANDE, S. M. R. (2018). Grandes eventos esportivos: impactos nas favelas do Rio de Janeiro. Bitácora Urbano Territorial, v. 28, n. 2, pp. 143-151.

FRENZEL, F; KOENS, K; STEINBRINK, M. (orgs.) (2012). Slum tourism: poverty, power and ethics. Londres/Nova York, Routledge.

GONÇALVES, R. (2013). Favelas do Rio de Janeiro: história e direito. Rio de Janeiro, PUC-Rio.

GUARESCHI, N. et al. (2002). As relações raciais na construção das identidades. Psicologia em estudo, v. 7, n. 2, pp. 55-64. 
GUASCO, P. P M. (2001). Num país chamado Periferia: Identidade e representação da realidade entre os" rappers" de São Paulo. São Paulo, EdUSP.

HALL, S; DU GAY, P. (eds.) (1996). Questions of cultural identity. Londres, Sage.

HARVEY, D. (2014). Cidades rebeldes: do direito à cidade à revolução urbana. São Paulo, Martins Fontes.

HOLSTON, J. (2013). Cidadania insurgente: disjunções da democracia e da modernidade no Brasil. São Paulo, Companhia das Letras.

JOVCHELOVITCH, S.; PRIEGO-HERNANDEZ, J. (2013). Sociabilidades subterrâneas: identidade, cultura e resistência em favelas do Rio de Janeiro. Brasília, Unesco.

KEISHA-KHAN, Y. P. (2004). The roots of black resistance: Race, gender and the struggle for urban land rights in Salvador, Bahia, Brazil. Social Identities, v. 10, n. 6, pp. 811-831.

KOWARICK, L. (1991). Cidade e Cidadania. São Paulo em perspectiva, v. 5, n. 2, pp. 2-8.

LEFEBVRE, H. (2001). O direito à cidade. São Paulo, Centauro.

MARICATO, E. (2017). O impasse da política urbana no Brasil. Petrópolis, Vozes Limitada.

MARSHALL, T. (1967). Cidadania, classe social e status. Rio de Janeiro, Zahar.

MIRAFTAB, F. (2004). Invented and invited spaces of participation: neoliberal citizenship and feminists' expanded notion of politics. Wagadu: Journal of Transnational Women's and Gender Studies. Disponível em: <http://sites.cortland.edu/wagadu/wp-content/uploads/sites/3/2014/02/ miraftab.pdf>. Acesso em: 15 jan 2019.

(2009). Insurgent planning: situating radical planning in the global south. Planning Theory, v. 8, n. 1, pp. 32-50.

(2016). Insurgência, planejamento e a perspectiva de um urbanismo humano. Revista Brasileira de Estudos Urbanos e Regionais, v. 18, n. 3, pp. 363-377.

(2020). Insurgency and Juxtacity in the Age of Urban Divides. Urban Forum, v. 31, n. 3, pp. 433-441.

MEAD, G. H. (1934). Mind, self and society. Chicago, University of Chicago Press.

ONU-HABITAT (2020). World Cities Report 2020. Disponível em: <https://unhabitat.org/sites/default/ files/2020/11/world_cities_report_2020_abridged_version.pdf>. Acesso em: dez 2020.

PATROCÍNIO, P. R. T. (2013). Escritos à margem: a presença de autores de periferia na cena literária brasileira. Rio de Janeiro, Faperj.

PERLMAN, J. E. (1977). O mito da marginalidade: favelas e política no Rio de Janeiro. Rio de Janeiro, Paz e Terra.

ROY, A. (2011). Slumdog cities: Rethinking subaltern urbanism. International Journal of Urban and Regional Research, v. 35, n. 2, pp. 223-238.

SANTOS, C. N. F. (1981). Movimentos urbanos no Rio de Janeiro. Rio de Janeiro, Zahar.

SANTOS, W. (1979). Cidadania e Justiça: a política social na ordem brasileira. Rio de Janeiro, Campus.

SOUSA SANTOS, B. (2002). A crítica da razão indolente: contra o desperdício da experiência. São Paulo, Cortez.

(2019). O fim do império cognitivo: a afirmação das epistemologias do Sul. São Paulo, Autêntica. 
VAINER, C.; BIENENSTEIN, R.; TANAKA, G. et al. (2013). O Plano Popular da Vila Autódromo: uma experiência de planejamento conflitual. In: XV ENANPUR. Anais... Recife.

VALLADARES, L. (2000). A gênese da favela carioca. A produção anterior às ciências sociais. Revista Brasileira de Ciências Sociais, v. 15, n. 44, pp. 5-34.

(2016). A invenção da favela: do mito de origem à favela.com. Rio de Janeiro, editora FGV.

WATSON, V. (2013). Planning and the "stubborn realities" of global south-east cities: Some emerging ideas. Planning Theory, v. 12, n. 1, pp. 81-100.

Texto recebido em 15/mar/2019

Texto aprovado em 15/maio/2019 
